\title{
Diabetes Insipidus and Galactorrhea Caused by Histiocytosis X
}

\author{
YUKIo HIRATA, Noboru SAKAMOTO, YoshIo YOSHIMOTO, \\ YuzUru KATO, SHIGERU MATSUKURA AND Hiroo IMURA
}

Third Division, Department of Medicine,
Kobe University School of Medicine, Kobe 650

\section{Synopsis}

A 44-year-old woman with diabetes insipidus of 3 years duration was found to have histiocytosis $\mathrm{X}$. This was based on clinical, radiological and pathological findings consistent with the diagnosis. Furthermore, she developed spontaneous galactorrhea during the course. Endocrine studies of hypothalamic-pituitary function revealed completely impaired secretion of gonadotropin, growth hormone and antidiuretic hormone, and possible partial impairment of adrenocorticotropic hormone secretion, while thyroid stimulating hormone secretion remained intact. Persistently elevated plasma levels of human prolactin were also demonstrated, which were unaffected by administration of either thyrotropin releasing hormone, $l$-DOPA or water loading, but suppressed significantly by CB-154, an ergot alkaloid. These results suggest that abnormalities of the patient's endocrine function may be mainly accounted for by a single hypothalamic lesion.

Histiocytosis $\mathrm{X}$ is a systemic disease of unknown etiology which affects almost every organ with pathological proliferation of reticuloendothelial cells, varying from histiocytic infiltration to granulomatous changes, to healing fibrosis (Lichtenstein, 1953).

Since histiocytic invasion in the central nervous system is usually limited to the hypothalamus, pituitary stalk and/or posterior pituitary, patients with this disorder may manifest clinical diabetes insipidus, anterior pituitary dysfunction and so forth (Avery et al., 1957; Helbock et al., 1971; Braunstein et al., 1972a,b). Such patients, therefore, provide a unique model for studying hypothalamic regulation of pituitary tropic hormone secretion in man.

This report describes a patient with diabetes insipidus caused by histiocytosis $\mathrm{X}$,

Received for publication April 3, 1975 who developed spontaneous galactorrhea during the course, and thorough endocrinological studies were performed to evaluate the hypothalamic-pituitary function in this disease.

\section{Materials and Methods}

\section{Test Procedures}

Endocrine function tests were usually started at 9:00 a.m. after overnight fasting. The function of hypothalamic-pituitary axis was examined as follows;

1. Posterior pituitary function was studied by the water deprivation test and vasopressin test (5 $\mathrm{U}$ of pitressin tannate in oil, intramuscularly).

2. Function of the hypothalamic-pituitary-adrenal axis was studied by the circadian rhythmicity of plasma ACTH, single-dose metyrapone test (1.5 $\mathrm{g}$, orally given at midnight), single-dose dexamethasone suppression test $(1.0 \mathrm{mg}$, orally given at midnight), insulin tolerance test $(0.1 \mathrm{U} / \mathrm{kg}$ body weight, intravenously), and rapid ACTH test $(0.25 \mathrm{mg}$ of synthetic $1-24 \mathrm{ACTH}$, intravenously). 
3. Human growth hormone (HGH) secretion was evaluated by its response to insulin-induced hypoglycemia, glucagon (1.0 mg, intravenously), arginine (30 g, infused intravenously over a period of $30 \mathrm{~min}$ ) and $l$-DOPA $(0.5 \mathrm{~g}$, orally).

4. Function of the hypothalamic-pituitary-thyroidal axis was studied by TRH stimulation test $(500 \mu \mathrm{g}$ of synthetic TRH, intravenously), protein bound iodine (PBI), Triosorb resin sponge uptake, serum thyroxine, effective thyroxine ratio (ETR), and ${ }^{131}$ I thyroid uptake $(24 \mathrm{hr})$.

5. Gonadotropin secretion was evaluated by its response to LH-RH stimulation test $(100 \mu \mathrm{g}$ of synthetic LH-RH, intravenously).

6. Human prolactin ( $\mathrm{HPr}$ ) secretion was evaluated by its response to TRH $(500 \mu \mathrm{g}$, intravenously), $l$-DOPA $(0.5 \mathrm{~g}$, orally), water load $(20 \mathrm{ml} / \mathrm{kg}$ body weight, orally), and CB-154 (Sandoz, Basle., 2.5 mg, orally).

Blood sampling was performed at 15 or $30 \mathrm{~min}$ intervals for $2 \mathrm{hr}$ or more. The heparinized blood was immediately centrifuged, and the plasma was stored at $-20^{\circ} \mathrm{C}$ until assayed.

\section{Assay Methods}

Plasma ACTH (Matsukura et al., 1971), HGH (Schalch and Parker, 1964), TSH (Odell et al., 1965), LH (Odell et al., 1967), FSH (Midgley, 1967) and HPr (Hwang et al., 1971) were determined by the specific radioimmunoassays. Highly purified human ACTH (Li), HGH (Wilhelmi), TSH (Calbiochem), HPr (Friesen), LH and FSH (the Second International Reference Preparation of Human Menopausal Gonadotropin; 2nd IRP-HMG, National Institute for Medical Research.) were used for standards.

Total serum thyroxine and plasma cortisol were determined by competitive protein-binding assays (Murphy and Pattee, 1964; Murphy, 1967).

The total $24 \mathrm{hr}$ urinary 17-hydroxycorticosteroid (17-OHCS) was measured by the method of Silber and Porter (1954).

Plasma and urinary osmolarity were determined by Fiske osmometer (freezing-point depresion) and blood glucose by Technicon Auto Analyzer.

\section{Case Report}

The patient, 44-year-old female, was admitted to this hospital in May, 1973, for further evaluation of her diabetes insipidus, intractable to conventional treatment.

She was well until September, 1970, when she noticed abrupt onset of thirst, always craving for cold water, accompanied by polyuria with daily urinary volume over 10 liter.

On the first admission to another hospital in May, 1971 , the diagnosis of diabetes insipidus was made without further evaluation of its etiology, and she was discharged in June, 1971. Her symptoms were ameliorated with the treatment of chlorpropamide and hydrochlorothiaziazide, and pitressin was not used since it caused her an allergic reaction. She subsequently noticed xanthomata developed insidiously on both eyelids and cervical region. In February, 1973, she complained again of polydipsia and polyuria which were not controlled by the conventional therapy, accompanied by fever of unknown origin, anorexia and malaise. Her menstruations had been regular until September, 1969, when she underwent total hysterectomy with bilateral oophorectomy because of uterine myoma. She denied any joint pains, pathological fractures, otitis media or exertional dyspnea.

Physical examination on admission revealed an obese middle aged female $(78 \mathrm{~kg}$ in weight, $157 \mathrm{~cm}$ in height) in a chronic distress. Xanthomata were noted in both eyelids and cervical region (Fig. 1.) and the liver was palpable 2 fingerbredths below the right costal margin without splenomegaly. Reduced axillary and pubic hair was noted. No pathological lymphadenopathy or exophthalmos was noted, and blood pressure was $120 / 60 \mathrm{mmHg}$. Ophthalmologic, gynecologic and ENT examinations were all negative.

Laboratory data showed persistenly elevated erythrocyte sedimentation rate $(60-100 \mathrm{~mm} / \mathrm{hr})$ and positive CRP reaction with fluctuating body temperature $\left(37-39^{\circ} \mathrm{C}\right)$ throughout the course, while the $\mathrm{CBC}$ and differential WBC were normal. Urinalysis showed no protein or glucose, although the specific gravity was 1.005 and urinary osmolarity was 80 $\mathrm{mOsm} / \mathrm{kg}$. Serum sodium was 143 , potassium 3.7 and chloride $98 \mathrm{mEq} /$ liter.

The oral glucose tolerance test showed normal blood glucose response. Serum protein electrophoresis and immunoglobulins showed no abnormality. Serological tests were negative for syphilis, cold agglutination, Paul-Bunnel, toxoplasmosis, Widal and RA. The titer of ASL-O was normal, and no significant rise of various viral titers was noted. The intermediate-strength PPD was positive. Cultures of blood and urine gave no bacterial or fungal growth.

Pulmonary, renal and liver function studies were all within normal limits. ECG tracings were normal, and the right cubital vein demonstrated normal venous pressure.

The lumbar puncture revealed normal CSF pressure with no remarkable change in protein or cells.

\section{Radiological Examination}

Chest X-ray revealed bilateral diffuse interstitial infiltration with hilar prominence. An upper GI $\mathrm{X}$-ray series was negative. Systemic bone X-ray series demonstrated multiple osteolytic lesions in the right scupula, femora, tibiae and fibulae (Fig. 3.): The long bones were involved only at the end of shafts, and these multicentric lytic lesions were sharply demarcated. Skull X-ray showed neither 
"geographic" lytic changes nor destruction of sella turcica. Ribs and pelvis were spared.

\section{Pathological Examination}

Biopsies of both the left cervical skin lesion and the right tibial bone lesion were performed. Microscopical examination of the skin specimens revealed histiocytic proliferation predominantly in dermis, mostly consisting of lipoid-laden macrophages or foamy cells with scanty eosinophilic infiltration and minimal granulomatous changes (Fig. 2.). The same changes were recognized in the bone lesion, though regressing and replaced by fibrosis (Fig. 4.).

\section{Clinical Course}

She developed spontaneous galactorrhea during the

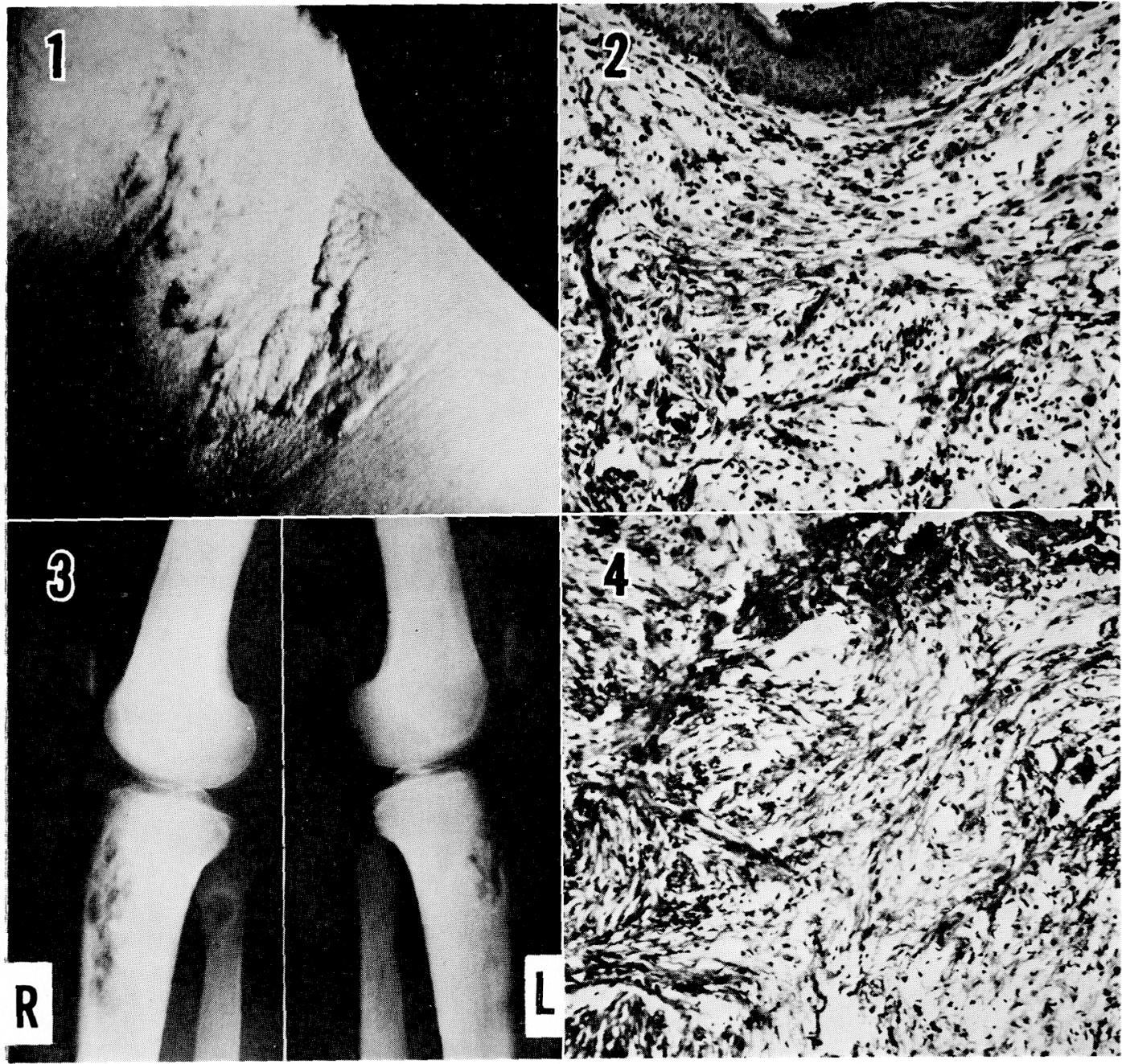

Fig. 1. Gross appearance of xanthomata in the left cervical region

Fig. 2. Photomicrograph of the skin lesion revealing histiocytic proliferation, being mostly composed of lipoid-laden macrophages with scanty eosinophilic infiltration and minimal granulomatous changes. ( $\mathrm{H} \& \mathrm{E}, \times 140)$

Fig. 3. Bone X-ray of knee joints revealing multicentric osteolytic changes of tibiae and right fibla

Fig. 4. Photomicrograph of right tibial bone lesion revealing the same histiocytic changes as seen in the skin lesion, though regressing and replaced by fibrosis. $(\mathrm{H} \& \mathrm{E}, \times 140)$ 
course, suggestive of hyperprolactinemia resulting from hypothalamic involvement, which was proven later by hypothalamic-pituitary function studies. She was treated with prednisolone $30 \mathrm{mg}$ /day as soon as the diagnosis was established and all endocrine studies completed. The steroid regimen had a dramatic effect, resulting in complete disappearance of her systemic symptoms and signs. She gained wellbeing, good appetite, and disappearance of fever with normal erythrocyte sedimentation rate and negative CRP reaction, although her galactorrhea and hyperprolactinemia persisted. On steroid treatment, her diabetes insipidus was controlled with a combination of chlorpropamide $(500 \mathrm{mg} / \mathrm{day})$ and hydrochlorothiazide $(100 \mathrm{mg} /$ day $)$. She is now, two years after discharge, doing well without recurrence.

\section{Results}

\section{Posterior pituitary function}

The patient failed to concentrate her urine above the level of plasma osmolarity after $7 \mathrm{hr}$ water deprivation. The final ratio of urinary to plasma osmolarity (Uosm/Posm) was 0.39, extremely low, indicating impaired anti-diuretic function. The vasopressin test at the first admission, which was not performed on this occasion because of her allergic history, demonstrated a significant rise of Uosm (from 181 to $480 \mathrm{mOsm} / \mathrm{kg}$ ) following intramuscular injection of $5 \mathrm{U}$ pitressin tannate in oil.

\section{Anterior pituitary function}

a) Hypothalamic-pituitary-adrenal function

$24 \mathrm{hr}$ urinary excretion of 17-OHCS was $6.5 \mathrm{mg}$. Circadian rhythm of plasma ACTH, elevated early in the morning and fallen in the evening, was noted (Fig. 5). Synthetic

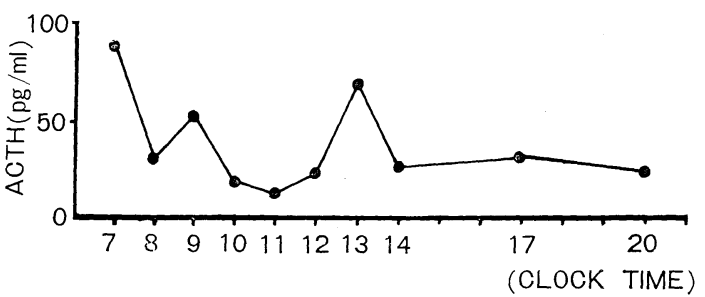

Fig. 5. Circadian rhythm of plasma ACTH. Normal values (9 AM $<120,9 \mathrm{PM}<30$ )
1-24 ACTH administered intravenously gave a two-fold increment of plasma cortisol levels. Single-dose metyrapone administered at midnight resulted in increased plasma ACTH levels next morning, while single-dose dexamethasone administered at midnight suppressed both ACTH and cortisol levels next morning (Table 1). Insulin induced hypoglycemia, on the other hand, caused no plasma cortisol response, although the basal level $(21.0 \mu \mathrm{g} / 100 \mathrm{~m} l)$ was elevated (Table 2$)$. b) $\mathrm{HGH}$ secretion

Basal HGH levels were always below $1 \mathrm{ng} / \mathrm{ml}$. In fact, no response of $\mathrm{HGH}$ occurred during any stimulation, such as insulin induced hypoglycemia, glucagon, arginine or $l$-DOPA (Table 2).

c) Hypothalamic-pituitary-thyroidal axis

All thyroid function studies were almost within normal limits. PBI $5.0 \mu \mathrm{g} / 100 \mathrm{~m} l$, total serum thyroxine $9.4 \mu \mathrm{g} / 100 \mathrm{ml}$, Triosorb resin sponge uptake $23.5 \%$, ETR 1.05 (normal $0.86-1.13$ ) and ${ }^{131} \mathrm{I}$-thyroid uptake (24 hr) 9.4\%. Furthermore, normal TSH response was noted after TRH stimulation (Table 3).

d) Gonadotropin secretion

Basal LH and FSH levels were low, despite of her bilateral oophorectomy in the past. However, response of gonadotropin secretion, though limited, occurred following LH-RH stimulation (Table 3).

Table 1. Pituitary-adrenal function tests

\begin{tabular}{ccc}
\hline & $\begin{array}{c}\text { Plasma ACTH Plasma cortisol } \\
(\mathrm{pg} / \mathrm{m} l)\end{array}$ & $\begin{array}{c}(\mu \mathrm{g} / 100 \mathrm{~m} l) \\
\text { Synthetic } 1 \text {-24 ACTH }\end{array}$ \\
0 Min & - & 15.0 \\
30 Min & - & 25.4 \\
$60 \mathrm{Min}$ & - & 39.0 \\
Metyrapone & & - \\
Before 8 AM & 45 & - \\
10 AM & 20 & - \\
After 8 AM & 360 & - \\
10 AM & 271 & 17.0 \\
Dexamethasone & & 5.7 \\
Before 9 AM & 53 & \\
After 9 AM & N.D.* & \\
* Not detectable $(<10 \mathrm{pg} / \mathrm{m} l)$ &
\end{tabular}


e) HPr secretion

Basal HPr levels were persistently elevated, ranging from 44 to $80 \mathrm{ng} / \mathrm{ml}$. No increment of HPr secretion occurred following TRH stimulation. Furthermore, plasma HPr levels were not suppressed by either $l$-DOPA administration or water loading, the maneuvers known to inhibit pituitary prolactin secretion in normal subjects. Administration of CB-154, however, resulted in a significant fall of plasma HPr levels (Table 4).

\section{Discussion}

The patient described here exhibited the clinical, radiological and pathological findings, which were all consistent with the diagnosis of histiocytosis X (Lichtenstein, 1953; Avery et al., 1957). A unique feature presented by this patient was the spontaneous galactorrhea which developed during the course. Since histiocytic involvement is usually limited to the hypothalamns, pitui-

Table 2. Glucose, cortisol and HGH levels durıng insulin tolerance and glucagon stimulation, and $\mathrm{HGH}$ levels during arginine and $l$-DOPA stimulation

\begin{tabular}{|c|c|c|c|c|c|c|c|c|c|}
\hline & Basal & 15 & 30 & 45 & 60 & 90 & 120 & 150 & $180(\mathrm{~min})$ \\
\hline \multicolumn{10}{|l|}{ Insulin } \\
\hline Glucose $(\mathrm{mg} / 100 \mathrm{ml})$ & 100 & 84 & 40 & 51 & 59 & 80 & 100 & - & - \\
\hline Cortisol $(\mu \mathrm{g} / 100 \mathrm{ml})$ & 21.0 & 19.0 & 22.8 & 20.0 & 21.4 & 18.4 & 28.0 & - & - \\
\hline $\mathrm{HGH}(\mathrm{ng} / \mathrm{m} l)$ & 0.2 & 0.2 & 0.3 & 0.4 & 1.0 & 0.5 & 1.0 & - & - \\
\hline \multicolumn{10}{|l|}{ Glucagon } \\
\hline Glucose $(\mathrm{mg} / 100 \mathrm{ml})$ & 78 & - & 160 & - & 112 & 66 & 60 & 68 & 74 \\
\hline $\mathrm{HGH}(\mathrm{ng} / \mathrm{ml})$ & $<0.2$ & - & $<0.2$ & - & $<0.2$ & $<0.2$ & 0.3 & $<0.2$ & 0.8 \\
\hline \multicolumn{10}{|l|}{ Arginine } \\
\hline HGH (ng/ml) & $<0.2$ & - & $<0.2$ & - & $<0.2$ & $<0.2$ & $<0.2$ & - & - \\
\hline \multicolumn{10}{|l|}{$l$-DOPA } \\
\hline $\mathrm{HGH}(\mathrm{ng} / \mathrm{ml})$ & $<0.2$ & - & $<0.2$ & - & $<0.2$ & $<0.2$ & $<0.2$ & $<0.2$ & $<0.2$ \\
\hline
\end{tabular}

Table 3. TSH levels during TRH stimulation and gonadotropin levels during LH-RH stimulation

\begin{tabular}{lrrrrrrr}
\hline & Basal & 15 & 30 & 45 & 60 & 90 & $120(\mathrm{~min})$ \\
\hline TRH & & & & & & & \\
TSH $(\mu \mathrm{U} / \mathrm{m} l)$ & 2.0 & 9.8 & 15.2 & 17.9 & 18.8 & 9.8 & 6.5 \\
\hline LH-RH & $<2.0$ & 10.1 & 7.7 & 9.7 & 11.2 & 10.5 & 5.8 \\
LH* $(\mathrm{mIU} / \mathrm{ml})$ & 2.0 & 6.0 & 6.6 & 4.1 & 8.2 & 15.0 & 4.5 \\
FSH $(\mathrm{mIU} / \mathrm{ml})$ & & &
\end{tabular}

Basal values: $* 8.3 \pm 0.9 \mathrm{mIU} / \mathrm{ml}($ mean $\pm \mathrm{SE})$ and $\uparrow 8.0 \pm 0.6 \mathrm{mIU} / \mathrm{ml}(\mathrm{mean} \pm \mathrm{SE})$ in 6 normal women during luteal and follicular phase; the 2nd IRP-HMG, National Institute for Medical Research, used as standards.

Table 4. HPr levels during TRH stimulation, l-DOPA suppression, water load and CB-154 administration

\begin{tabular}{lcrrrrrrr}
\hline \hline & Basal & 15 & 30 & 60 & 90 & 120 & 150 & $180(\mathrm{~min})$ \\
\hline HPr* $(\mathrm{ng} / \mathrm{ml})$ & & & & & & & & \\
TRH & 44 & 60 & 52 & 58 & - & 49 & - & - \\
l-DOPA & 48 & - & 43 & 47 & 38 & 48 & 46 & 59 \\
Water Load & 58 & - & 88 & 90 & 94 & 98 & 104 & 104 \\
\hline & Basal & 1 & 2 & 3 & 4 & 5 & $6(\mathrm{hr})$ & \\
\hline CB-154 & 80 & 68 & 23 & 32 & 23 & 28 & 27 \\
\hline
\end{tabular}

* Basal values: $11.4 \pm 1.3 \mathrm{ng} / \mathrm{ml}$ (mean $\pm \mathrm{SE}$ ) in 32 normal subjects. 
tary stalk and/or posterior pituitary in the absence of anterior pituitary destruction (Avery et al., 1957; Helbock et al., 1971; Braunstein and Kohler, 1972b), this patient provided a unique opportunity to investigate the effect of the hypothalamic lesion on pituitary function.

Pituitary-adrenal axis was normal so far as $24 \mathrm{hr}$ urinary $17-\mathrm{OHCS}$ excretion and adrenal responsiveness to ACTH were concerned. ACTH secretion modulated by the mechanism of circadian rhythmicity and negative feedback seemed to remain intact. The lack of ACTH secretion during insulininduced hypoglycemic stress raises two possibilities. First, the hypothalamic areas regulating corticotropin releasing factor (CRF) might be partially involved by histiocytic invasion since the dissociation of impaired ACTH secretion by different stimuli is reported (Faglia et al., 1973). Second, the present results of hypoglycemic stress might be invalid because the elevated basal level of plasma cortisol may not preclude the fortuitous unresponsiveness to the provocation. Therefore, repeated tests with hypoglycemic stress or other provocations, such as lysine-vasopressin and pyrogen, should be performed under the basal state to solve these possibilities. On the other hand, HGH failed to secrete during any of the provocation tests performed, indicating complete involvement of the hypothalamic areas to release growth hormone releasing factor (Braunstein et al., 1972a, b ; Gates et al., 1973). Hypothalamic-pituitary-thyroidal axis, however, was well preserved, indicating no involvement. The results of both low basal levels of plasma gonadotropin and response of gonadotropin secretion, though limited, to LH-RH administered intravenously, strongly suggested the secondary dysfunction of anterior pituitary resulting from long-term LH-RH deficiency.

Basal HPr was found to be persistently elevated as expected from the spontaneous galactorrhea. HPr secretion is believed to be regulated predominantly by hypothalamic prolactin inhibiting factor (PIF) (Turkington et al., 1971; Meites et al., 1972), of which deficiency from any cause may result in hyperprolactinemia. Thus, her hyperprolactinemia further gave evidence of hypothalamic lesion. TRH, known to stimulate secretion of HPr as well as that of TSH (Bowers et al., 1971; Jacob et al., 1971), failed to elevate HPr level any more in this case. Since TRH is believed to act at the pituitary level to secrete prolactin in man and animal (Bowers et al., 1971; Jacob et al., 1971), it seemed to be plausible that prolactin producing cells became refractory to further stimulation by TRH.

The fact that administration of $l$-DOPA and water load, reported to inhibit $\mathrm{HPr}$ secretion in normal subjects and patients with functional galactorrhea through acting on release of hypothalamic PIF (Friesen et al., 1972; Turkington, 1972; Buckman et al., 1973), failed to suppress plasma $\mathrm{HPr}$ levels in this case, suggested impaired function of the hypothalamus to release PIF in response to those stimuli.

Significant suppression of plasma $\mathrm{HPr}$ levels following administration of CB-154 (2-Br- $\alpha$-ergorcyptine) seemed to be reasonable because this drug is believed to inhibit secretion of prolactin through acting at the pituitary level (Lu et al., 1971; Del Pozo et al., 1972).

Deficient secretion of anti-diuretic hormone also indicated histiocytic invasion of the hypothalamus, pituitary stalk and/or posterior pituitary (Helbock, et al., 1971; Braunstein and Kohler, 1972b).

Therefore, thorough endocrine evaluation of hypothalamic-pituitary function revealed that histiocytic involvement was limited to the hypothalamus, pituitary stalk and/or posterior pituitary, resulting in secondary diabetes insipidus, partial anterior pituitary dysfunction, and galactorrhea. Furthermore, it was suggested that the hypothalamic areas involved in regulation (releasing and/or 
inhibiting) of secretion of pituitary tropic hormones are separated from each other since disparities were observed in secretion of tropic hormones, probably depending on the extent of histiocytic infiltration in the hypothalamus.

To our knowledge, this patient with histiocytosis $\mathrm{X}$ was the first case reported in which thorough endocrine studies were performed, using radioimmunoassay techniques to measure the pituitary tropic hormones known at present. In a series of 13 patients with Hand-Schüller-Christian disease (Braunstein and Kohler, 1972b), impaired secretion of $\mathrm{HGH}$ was found in 10 patients in whom diabetes insipidus was usually present. These results are in agreement with ours. Later studies (Braunstein et al., 1972a), showed that 8 of 13 patients exhibited hyperprolactinemia and the elevated plasma levels of HPr in 3 of 8 patients were not suppressed by administration of $l$-DOPA. These 3 patients might have the same hypothalamic lesions as the present case, in whom inappropiate function of the hypothalamus to release PIF in response to those stimuli was suggested. The patient reported by Gates et al. (1973) had also hyperprolactinemia, although further evaluation was not performed. Their autopsy findings, however, were interesting; focal histiocytic infiltration was found in the posterior hypothalamus, whereas almost complete replacement by histiocytic infiltration was found in the posterior pituitary. The anterior pituitary was spared from involvement, being abundant in prolactin producing cells and deficient in GH producing cells. Therefore, similar pathological changes are expected to be found in the hypothalamus of the present case.

In conclusion, thorough investigation of hypothalamic pituitary function in patients with this disorder is useful to assess the extent of histiocytic infiltration in the hypothalamus, and to study the hypothalamic regulation of pituitary tropic hormone secretion in man.

\section{Acknowledgement}

The authors wish to thank Dr. S. Okada, Department of Pathology, Central Clinical Laboratory, Kobe University Hospital, for the pathological examination of this patient's biopsy specimens. We are greatly indebted to Dr. C. H. Li, University of California, San Francisco Medical Center, who supplied highly purified human ACTH, and Dr. H. G. Friesen, McGill University Clinic, Royal Victoria Hospital, Montreal, who supplied both human prolactin and anti-HPr serum. Thanks are also due to National Institute for Medical Research, for providing 2nd IRP-HMG.

\section{References}

Avery, M. E., J. G. McAfee and H. G. Guild (1957). Am. J. Med. 22, 636.

Bowers, C. Y., H. G. Friesen, P. Hwang and H. J. Guyda (1971). Biochem. Biophys. Res. Commun. 45, 1033.

Braunstein, G. D., W. E. Bridson and P. O. Kohler (1972a). Clin. Res. 20, 422.

Braunstein, G. D. and P. O. Kohler (1972b). New Engl. J. Med. 286, 1225.

Buckman, M. T., N. Kaminsky, M. Conway and G.T. Peake (1973). J. Clin. Endocrinol. Metab. 36, 911.

Del Pozo, E., R. Brun del Re, L. Varga and H. G. Friesen (1972). Ibid. 35, 768.

Faglia, G., A. Ambrosi, P. Beck-Peccoz and P. Travaglini (1973). Acta Endocr. (Kbh). $72,223$.

Friesen, H.G., H. Guyda, P. Hwang, J. Tyson and A. Barbeau (1972). J. Clin. Invest. 51, 706.

Gates, R.B., H.G. Friesen and N.A. Samaan (1973). Acta. Endocr. (Kbh). 72, 101.

Helbock, H., W. Krivit and M. E. Nesbit (1971). J. Lab. Clin. Med. 78, 194.

Hwang, P., H. Guyda and H. G. Friesen (1971). Proc. Nat. Acad. Sci. U.S.A. 68, 1902.

Jacob, L. S., P. J. Synder, J. F. Wilber, R. D. Utiger and W. H. Daughaday (1971). J. 
Clin. Endocrinol. Metab. 33, 996.

Lichtenstein, L. (1953). AMA Arch. Pothol. 56, 84.

Lu, H., Y. Koch and J. Meites (1971). Endocrinology 89, 229.

Matsukura, S., C. D. West, Y. Ichikawa, W. Jubiz, G. Harada and F. H. Tyler (1971). J. Lab. Clin. Med. 77, 490.

Meites, J., K.H. Lu, W. Wutlke, C.W. Welsh, H. Nakagawa and S. K. Quadre (1972). Recent Progr. Horm. Res. 28, 471.

Midgley, A. R. (1967). J. Clin. Endocrinol. Metab. 27, 295.

Murphy, B. E. F. and C. J. Pattee (1964). Ibid. 24, 187.

Murphy, B. E. F. (1967). Ibid. 27, 973.
Odell, W. D., J. F. Wilber and W. E. Paul (1965). Ibid. 25, 1179.

Odell, W. D., G. T. Ross and P. L. Raybord (1967). J. Clin. Invest. 46, 248.

Schalch, D. S. and M. L. Parker (1964). Nature 203, 1141.

Silber, R. H. and C. C. Porter (1954). J. Biol. Chem. 210, 923.

Tashjian, A. H., N. J. Barowsky and P. K. Jensen (1971). Biochem. Biophys. Res. Commun. 43, 516.

Turkington, R. W., L. E. Anderwood and J. J. VanWyk (1971). New Engl. J. Med. 285, 707.

Turkington, R. W. (1972). J. Clin. Endocrinol. Metab. 34, 306. 